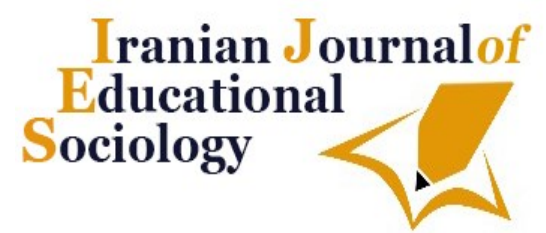

Iranian Journal of Educational Sociology

(Interdisciplinary Journal of Education)

Available online at: http://www.iase-idje.ir/

Volume 4, Number 1, March 2021

\title{
The Effect of Participative Management and Self-regulation on Conflict Management of Managers with Mediate Role of Spiritual Transcendence
}

\author{
Zeinab Begham ${ }^{1}$, Roghieh Vahdat Bourashan ${ }^{2 *}$, Mohammad Hassani ${ }^{3}$ \\ 1. PhD Student of Educational Management, Department of Educational Sciences, Urmia Branch, Islamic Azad University, Urmia, \\ Iran. \\ 2. Assistant Professor, Department of Educational Sciences, Urmia Branch, Islamic Azad University, Urmia, Iran. \\ 3. Professor, Department of Educational Sciences, Faculty of Literature and Humanities, Urmia University, Urmia, Iran.
}

\section{Article history:}

Received: 2020/05/27

Accepted: 2020/09/16

Published: 2021/03/21

\section{Keywords:}

Participative management, Self-

Regulation, Conflict Management, Spiritual Transcendence

\begin{abstract}
Purpose: The aim of this research was investigate the effect of participative management and self-regulation on conflict management of managers with mediate role of spiritual transcendence.

Methodology: The present study is applied in terms of purpose and in terms of implementation, it was descriptive-correlation. The research statistical population was the male and female teachers of one and two districts of Urmia city in 2019-20 academic years. According to the Cochran's formula, 343 people were selected as the sample by the stratified sampling method based on the service area. The research instruments was the questionnaires of participative management (Feyzi \& et al, 2009), self-regulation (Bouffard \& et al, 1995), conflict management (Thomas \& Kilmann, 1974) and spiritual transcendence (Piedmont, 1999). Data were analyzed with methods of Pearson correlation coefficients and structural equation modeling in SPSS-19 and Smart PLS-3 software.

Findings: The findings showed that participative management and selfregulation on spiritual transcendence, and participative management, self-regulation and spiritual transcendence on conflict management had a positive and direct effect. Also, participative management and selfregulation with mediating spiritual transcendence on conflict management had a positive and indirect effect $(\mathrm{P}<0.05)$. Studies have shown that the research the model had the fit well.

Conclusion: Spiritual transcendence was a good mediator between participatory management and self-regulation with conflict management, so according to the results to improve conflict management of managers can improve the level of their participative management, self-regulation and transcendence through training workshops.
\end{abstract}

Please cite this article as: Begham Z, Vahdat Bourashan R, Hassani M. (2021). The Effect of Participative Management and Self-regulation on Conflict Management of Managers with Mediate Role of Spiritual Transcendence. Iranian Journal of Educational Sociology. 4(1): 68- 77.

\footnotetext{
* Corresponding Author: r.vahdat_77@yahoo.com
} 


\section{Introduction}

Management in education and schools with the participation of all school staff and school associations in school administration and management is one of the essential processes for proper school management (Silvius, 2017). In the management debate, conflict is a normal thing that always happens and occurs when two or more goals, values, beliefs, needs and wants are in conflict with each other (Caber \& et al, 2019). Although conflicts are often seen as negative, when they can be managed with appropriate and effective strategies and strategies, they can have positive effects and consequences for personal growth and development (Rogers, Ha, Byon \& Thomas, 2020). . Conflict management means using conflict resolution techniques correctly when confronted with conflict (Hastings, Kavookjian \& Ekong, 2018). Proper conflict management allows people to be familiar with new developments and to use appropriate solutions to deal with threats and seize opportunities (Andreoni \& Chang, 2019).

One of the factors related to conflict management is participatory management (Sandstrom \& et al, 2003). Participation is an intellectual system that is established in society through education and means that individuals of a group or organization participate in the activities of that group or organization (Behmel, Damour, Ludwig \& Rodriguez, 2018). In a more comprehensive definition, participation is a kind of communication action means a collective effort in an organizational framework in which members seek to achieve their goals by pooling resources (Jago, 2017). Collaborative management is based on the cooperation and voluntary participation of employees and wants to use their ideas, opinions and initiatives in solving problems and issues of the organization (Rolkova \& Farkasova, 2015). Participatory management in the education organization is important because it increases the level of creativity and innovation in the organization, increases job satisfaction, increases teamwork, increases the level of motivation and strengthens self-confidence (Ormond, Telhada \& Putnik, 2019).

Another factor related to conflict management is self-regulation (Entezami Bayan, Ahghar \& Shabani, 2017). Self-regulation is not a fixed feature, but a set of environmentally related processes of orderly and planned thoughts, feelings, and actions to achieve goals (Memmott-Elison, et all, 2020). Self-regulation is the ability to control, modulate and adapt emotions, impulses and desires, which include cognitive and motivational processes, physiological and social variables affecting the control of purposeful actions (Muller \& Seufert, 2018). People with low self-regulation have difficulty controlling their emotions, have more external motivation and less internal motivation, and are more vulnerable to challenges in their personal and professional lives (Vega \& et al, 2020). Spiritual excellence can mediate between participatory management and self-regulation with conflict management. Spiritual excellence is the effort of the individual to have a mental and social view of life and to construct a broad meaning and concept of the ultimate goal of life and death (Piedmont, 2013). It is an internal and fundamental motivational structure that helps human beings to connect the separate parts of life and create a meaningful whole for life (Taghizadeh \& et al, 2017). High spiritual excellence can play a role in increasing life satisfaction, improving adjustment, reducing the perception of negative emotions, and increasing positive emotions (Lace, Haeberlein \& Handal, 2017).

Little research has been done on the relationship between participatory management, self-regulation, spiritual excellence, and conflict management, and sometimes even conflicting results. For example, the results of Jafari \& Mollaei (2019) showed that spiritual intelligence and self-regulation had a significant relationship. Viseh \& Kimiagar (2017) while researching concluded that spiritual excellence had a significant positive effect on conflict management. Entezami Bayan \& et al (2017) concluded in a study that selfregulation had a significant effect on conflict management. In another study, Arman, Ahmadi \& Khosravilaghab (2015) reported that spiritual intelligence and conflict management had a positive and significant relationship. The results of Salimi, Karaminia \& Esmaeili (2011) showed a positive and significant relationship between participatory management and conflict management. Farzadnia (2012) while researching concluded that self-regulation had a significant positive effect on conflict management. In 
another study, Kordi \& Aftab Azari (2010) reported that participatory management and workplace spirituality had a positive and significant relationship. Etebarian \& Poorvali (2008) in a study concluded that self-regulation had a positive and significant relationship with conflict management. In addition, the results of Qaysi (2018) showed that there was a significant positive relationship between self-regulation and conflict management. Vashisht, Singh \& Sharma (2018) concluded in a study that self-regulation had a significant positive relationship with conflict management. In another study, Ebrahimi (2014) reported that there was a positive and significant relationship between participatory management and conflict management. In contrast, Tourani, Ahmadi \& Karami (2014) concluded in a study that there was no significant relationship between conflict and self-regulation.

Although previous studies have examined the simple relationship between variables and managers' conflict management, they have paid less attention to cause-and-effect relationships. The same purpose is designed. One of the challenges observed in previous studies is the difference in research results that sometimes the relationship between variables and conflict is significant and sometimes non-significant and to conclude whether these relationships are significant or not, more research is needed that this study has tried to investigate. Also, less recent research has designed and proposed strategies based on participatory management, self-regulation, and spiritual excellence to improve conflict management, and this research is unique in this area. Therefore, the present study aimed to investigate the effect of participatory management and self-regulation on managers' conflict management with the mediating role of spiritual excellence from the perspective of teachers.

\section{Methodology}

The present study was a correlational descriptive study in terms of applied purpose and data collection method. The statistical population of the study was 3167 male and female teachers in districts 1 and 2 of Urmia in the 2019-20 academic years. Cochran's formula was used to determine the sample size. According to the $95 \%$ confidence level, the amount of error allowed was 0.05 and the population size was 3167 , the sample size was 343 people who were selected by stratified sampling method based on the area of service. In this sampling method, after determining the population size in zones 1 and 2, its ratio was calculated and in the same proportion, samples from the mentioned zones were selected by random method. The research process was as follows: after approving the proposal and receiving a letter of introduction from the Islamic Azad University, Urmia Branch, he referred to the education of districts 1 and 2 of Urmia city and after coordination with its officials, teacher statistics were prepared and sampling was done. Finally, after stating the importance and necessity of the research and receiving the consent of the conscious participant in the research, they were asked to answer the questionnaires accurately and realistically after reading. In this study, in addition to the demographic information form including gender, place of work, background and education, the following questionnaires were used to collect data.

Participatory Management Questionnaire: This questionnaire was designed by Feyzi, Chopani \& Hayat (2009) with 16 items. Items are scored using a five-point Likert scale $(1=$ strongly disagree to $5=$ strongly agree) and a higher score indicates more participatory management. Feyzi et al. (2009) confirmed the validity of instrument structure by factor analysis method and the instrument had five factors of decision making, communication, leadership, structure and supervision and its reliability by Cronbach's alpha method for the mentioned dimensions were $0.58,0.65$ and 70 , respectively. Reported $0.73,0.73$ and 0.74 and for the whole instrument 0.85 . In the present study, the reliability value of Cronbach's alpha method for participatory management questionnaire was 0.89 .

Self-regulatory questionnaire: This questionnaire was designed by Bouffard, Boisvert, Vezeau \& Larouche (1995) with 14 items. Items are scored using a five-point Likert scale $(1=$ strongly disagree to 5 $=$ strongly agree) and a higher score indicates more self-regulation. Bouffard, et al (1995) confirmed the construct validity of the instrument by factor analysis and the instrument had three metacognitive, 
cognitive and motivational factors and its reliability by Cronbach's alpha method was 0.78. In Iran, Fallahi, Mikaeli, Atadokht \& Ahmadi (2019) reported the reliability of the instrument by Cronbach's alpha method of 0.80. In another study, Ghorbani \& Foolad Chang (2015) reported the internal consistency of the instrument through the correlation coefficient of factors with the whole instrument for metacognitive, cognitive and motivational factors of $0.82,0.64$ and 0.48 , respectively. In the present study, the reliability value of Cronbach's alpha for the self-regulatory questionnaire was 0.87 .

Conflict Management Questionnaire: This questionnaire was designed by Thomas \& Kilmann (1974) with 20 items. Items are scored using a five-point Likert scale $(1=$ strongly disagree to $5=$ strongly agree) and a higher score indicates more appropriate conflict management. Thomas \& Kilmann (1974) confirmed the validity of the instrument through the correlation coefficient of items with the total test score and its reliability by Cronbach's alpha method of 0.78. In Iran, Hasanpour, Izadian, Izadian \& Gholami Motlagh (2015) confirmed the content validity of the instrument based on the agreement of experts, experts and professors and reported its reliability by Cronbach's alpha method of 0.86 . In the present study, the reliability value of Cronbach's alpha for conflict management questionnaire was 0.91.

Spiritual Excellence Questionnaire: This questionnaire was designed by Piedmont (1999) with 19 items. Items are scored using a five-point Likert scale $(1=$ strongly disagree to $5=$ strongly agree $)$ and a higher score indicates greater spiritual excellence. Piedmont (1999) confirmed the construct validity of the instrument by factor analysis and the instrument had three factors of spiritual camaraderie, unity and integrity and spiritual connection and its total reliability by Cronbach's alpha method was 0.84. In Iran, Abolghasemi, Ariapooran \& Taherifard (2016) reported the reliability of the instrument by Cronbach's alpha method of 0.74 . In the present study, the convergent validity of the instrument with AVE index for the variables of participatory management was 0.70 , self-regulation was 0.84 , conflict management was 0.68 and spiritual excellence was 0.76 , which was confirmed due to being higher than 0.5 . In the present study, the reliability value of Cronbach's alpha method for the Spiritual Excellence Questionnaire was 0.84.Data were collected by the above questionnaires and analyzed by Pearson correlation coefficient and structural equation modeling in SPSS and Smart PLS software.

\section{Findings}

In the present study, 343 subjects were present and their demographic information was presented in Table 1 based on gender, region, history and education.

Table1. Demographic information of the subjects based on gender, background and education

\begin{tabular}{|c|c|c|c|}
\hline Attributes & Levels & Abundance & Frequency \\
\hline \multirow[t]{2}{*}{ Gender } & Female & 146 & $42 / 57 \%$ \\
\hline & Man & 197 & $57 / 43 \%$ \\
\hline \multirow[t]{2}{*}{ District } & area 1 & 175 & $51 / 02 \%$ \\
\hline & Area 2 & 168 & $48 / 98 \%$ \\
\hline \multirow[t]{6}{*}{ History } & 5-1 years & 22 & $6 / 41 \%$ \\
\hline & $10-6$ years & 28 & $8 / 16 \%$ \\
\hline & 15-11 years & 63 & $18 / 37 \%$ \\
\hline & 20-16 years & 71 & $20 / 70 \%$ \\
\hline & 25-21 years & 98 & $28 / 57 \%$ \\
\hline & 30-26 years & 61 & $17 / 78 \%$ \\
\hline \multirow[t]{4}{*}{ education } & Associate & 56 & $16 / 33 \%$ \\
\hline & Bachelor & 130 & $37 / 90 \%$ \\
\hline & Masters & 150 & $43 / 73 \%$ \\
\hline & $\mathrm{PhD}$ & 7 & $2 / 04 \%$ \\
\hline
\end{tabular}

The results showed that most of the teachers were male (57.43\%), in District One (51.02\%), with a history of 21-25 years (28.57\%) and with a master's degree (43.73\%). Was work (Table 1), Mean standard 
deviation and correlation coefficients of the variables of participatory management, self-regulation, spiritual excellence and conflict management were presented in Table 2.

Table2. Mean standard deviation and correlation coefficients of research variables

\begin{tabular}{|c|c|c|c|c|c|c|}
\hline Variables & Average & Standard deviation & 1 & 2 & 3 & 4 \\
\hline 1. Participatory management & $3 / 18$ & $0 / 76$ & 1 & & & \\
\hline 2. Self-regulation & $2 / 89$ & $0 / 64$ & $0 / 50^{* *}$ & 1 & & \\
\hline 3. Spiritual excellence & $2 / 92$ & $0 / 54$ & $0 / 61^{* *}$ & $0 / 55^{* *}$ & 1 & \\
\hline 4. Conflict management & $3 / 07$ & $0 / 69$ & $0 / 58^{* *}$ & $0 / 57^{* *}$ & $0 / 70^{* *}$ & 1 \\
\hline
\end{tabular}

The results showed that the relationship between all research variables, ie participatory management, self-regulation, spiritual excellence and conflict management are significant at a level less than 0.01 (Table 2). Examination of the assumptions of the analysis method showed that the hypothesis of normality of data for all four variables was confirmed by Kolmogorov-Smirnov test $(\mathrm{P}<0.05)$ and the assumption of sufficient correlation between variables to model structural equations is also based on Table 2. The fit indicators of the fitted model of the impact of participatory management and self-regulation on the management of managers' conflict with the mediating role of spiritual excellence were presented in Table 3.

Table3. Fit indicators of the fitted model the effect of participatory management and self-regulation on the management of managers' conflict with the mediating role of spiritual excellence

\begin{tabular}{ccccccc}
\hline Indicators & $\chi^{2} / \mathrm{df}$ & RMSEA & GFI & AGFI & CFI & NFI \\
\hline Statistics & $2 / 09$ & $0 / 01$ & $0 / 97$ & $0 / 96$ & $0 / 99$ & $0 / 99$ \\
\hline
\end{tabular}

\begin{tabular}{lllllll}
\hline Acceptance limit & Less than 3 & Less than 0.05 & More than 0.95 & More than 0.95 & More than 0.95 & More than 0.95
\end{tabular}

The results showed that the fitted model was due to the values of the chi-square index to the degree of freedom $\left(\chi^{2} / \mathrm{df}\right)$, the root mean square index of the estimation error (RMSEA), the goodness-fit index (GFI), the modified goodness index (AGFI), the adaptive fit index ( $\mathrm{CFI}$ ) and the standardized fit index (NFI) have a good fit (Table 3). As a result, the fitted model of conflict management based on participatory and self-regulatory management with the mediating role of spiritual excellence along with the standard coefficients of paths is presented in Figure 1.

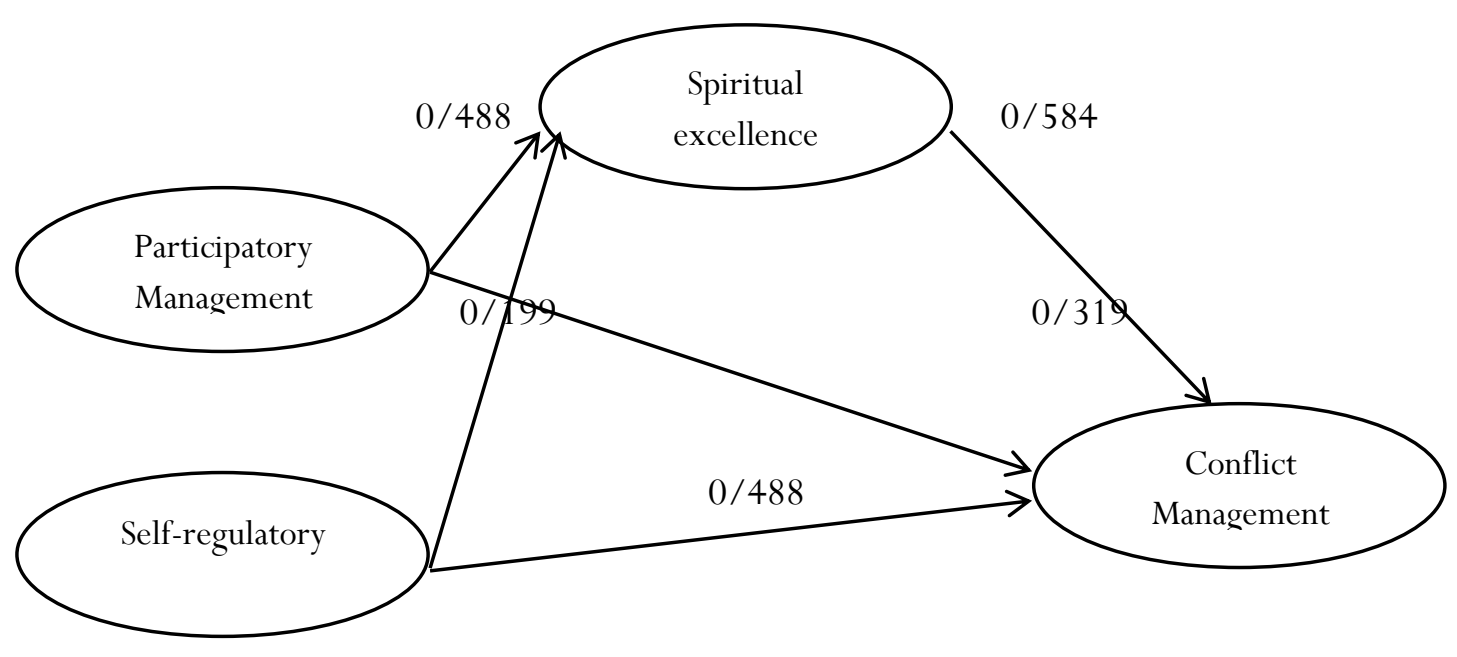

Figure1. Fitted model of the effect of participatory management and self-regulation on managers' conflict management with the mediating role of spiritual excellence with standard path coefficients

The results of standard path coefficients for the effect of participatory management and self-regulation on spiritual excellence and the effect of participatory management, self-regulation and spiritual excellence on conflict management can be seen (Figure 1). Therefore, the results of the research hypotheses were presented in Table 4. 
73| The Effect of Participative Management and...Volume 4, Number 1, 2021

Table4. Results of research hypotheses

\begin{tabular}{cccc}
\hline theories & $\begin{array}{c}\text { Path } \\
\text { coefficient }\end{array}$ & Amara t & meaningful \\
\hline 1. Participatory management has a direct impact on spiritual excellence. & $0 / 488$ & $3 / 977$ & $<0 / 05$ \\
\hline 2. Self-regulation has a direct effect on spiritual excellence. & $0 / 199$ & $2 / 815$ & $<0 / 05$ \\
\hline 3. Participatory management has a direct impact on conflict management. & $0 / 319$ & $2 / 905$ & $<0 / 05$ \\
\hline 4. Self-regulation has a direct impact on conflict management. & $0 / 488$ & $3 / 977$ & $<0 / 05$ \\
\hline 5. Spiritual excellence has a direct impact on conflict management. & $0 / 584$ & $5 / 343$ & $<0 / 05$ \\
\hline 6. Participatory management through spiritual excellence has an indirect effect on \\
conflict management. & $0 / 284$ & $12 / 510$ & $<0 / 05$ \\
\hline 7. Self-regulation through spiritual excellence has an indirect effect on conflict \\
management.
\end{tabular}

The results showed that participatory and self-regulatory management have a positive and direct effect on spiritual excellence, participatory management, self-regulation and spiritual excellence have a positive and direct effect on conflict management, and participatory and self-regulatory management have a positive and indirect effect on conflict management. They are significant at the level less than 0.05 (Table $4)$.

\section{Discussion}

Considering that improving and promoting conflict management has a fundamental role in the performance of any organization, so the present study was conducted to investigate the impact of participatory management and self-regulation on managers' conflict management with the mediating role of spiritual excellence. Findings showed that participatory management had a positive and direct effect on spiritual excellence. This finding was consistent with the findings of Kurdish and Aftab Yazdi (2010). Explaining this finding based on the research of Rajabi Farjad, Eghbalpur (2017), it can be said that participation is an intellectual system that is established in society through education. In fact, the culture of participation must be established in education and become a permanent and inseparable process from school. So, if we move towards participation in human resource management and get out of the selfcentered system of management, we can create the necessary ground for growth, initiative and prevention of indifferent resources. Collaborative management also creates the enthusiasm to work as a team and responsibly, and makes management employees consider the group as a friend, like-minded and close colleague, and actively work and cooperate with him. As a result, the above factors cause the increase of spiritual excellence with the increase of participatory management.

Other findings showed that self-regulation had a positive and direct effect on spiritual excellence. This finding was consistent with the findings of Jafari \& Mollaei (2016). Explaining this finding based on the research of Fallahi \& et al (2019), it can be said that self-regulation is one of the categories in which the role of the individual in the regulation of emotion is considered. To put it another way, self-regulation does not mean suppressing emotions and that we build a defensive barrier against our emotions and arousals, but it helps us choose how to instrument our emotions and feelings. People with good self-regulation can easily reduce the social pressures of friends, coworkers, and peers, recognize their emotions, have less stress with better planning, and use spiritual strategies. Another important point is that people are more compatible in their personal and professional lives and overcome problems alone and using coping strategies, both religious and non-religious, or seek help from others to solve problems and challenges. As a result, it can improve spiritual excellence through self-regulation through the processes described.

Also, the findings showed that participatory management had a positive and direct effect on conflict management. This finding was consistent with the findings of Salimi \& et al (2011) and Ebrahimi (2014). Explaining this finding based on Ebrahimi (2014) research, it can be said that participatory management is a function beyond effort and individual and even the sum of individuals, which leads to the development and improvement of the organization. Another important point is that participation is one of the life-giving, 
dynamic and refreshing factors in organizations, without which network connections are not created in the organization and there can be no collective thought and action, and without it the organization cannot move from the status quo to the desired status, but If there is partnership and participatory management, we will have a dynamic organization in which everyone works together to overcome problems and challenges and bring the organization to the desired goals and high level. As a result, participatory management will play an effective role in increasing conflict management.

Other findings showed that self-regulation had a positive and direct effect on conflict management. This finding is consistent with the findings of Entezami Bayan \& et al (2017), Farzadnia (2012), Etebarian \& Poorvali (2008), Qaysi (2018) and Vashist \& et al (2018) and with the findings of Tourani \& et al (2014) It was inconsistent. Probably the reason for the discrepancy between the present study and Tourani \& et al (2014) is due to differences in the research population, small sample size and number of centers for sample selection. In their research, due to the limited number of head nurses and nurses in the emergency department of medical centers of Iran University of Medical Sciences, all of them were selected by census as a sample and research was conducted on all of them, but the present study was conducted on teachers. Emergency nurses and nurses face a lot of stress and tension compared to teachers, and these differences in their research with the current study may have caused differences in the results. Explaining this finding based on the theory of self-regulated learning, it can be said that self-regulation is based on how people organize their learning in terms of cognitive, metacognitive, motivational and behavioral beliefs. Selfregulation is also information processing activity in which information is about the structure of behavior, and this structure means that the person acquires skills to design, control and guide their learning process and evaluate and monitor their learning process and performance. Think and act on ways to correct it. As a result, the above factors increase the level of conflict management by increasing self-regulation.

Other findings showed that spiritual excellence had a positive and direct effect on conflict management. This finding was consistent with the findings of Viseh \& Kimiagar (2017), Arman \& et al (2015). Explaining this finding based on Khoshtinat (2014) research, it can be said that spirituality is one of the inner needs of human beings that exists in hearts and minds and in mirrors, especially in religious mirrors. Given that spirituality is the ultimate realm and concern, and that all human beings have the ultimate concern, then all human beings are spiritual. Of course, there are various interpretations of the final concern, but most psychologists have defined spirituality as a constant human effort to respond to the whys of life, because spiritual excellence is an individual's attempt to construct a broad meaning of the ultimate goal of life and death. In other words, one's talent is to stand out from the present time and place and see life from a larger and more objective perspective. Therefore, with the help of spiritual excellence, people use their religious and spiritual beliefs and rituals to face the problems and pressures of life, so with the increase of spiritual excellence, the level of conflict management improves.

In addition, the findings showed that participatory management and self-regulation through spiritual excellence had a positive and indirect effect on conflict management. Explaining this finding, it can be said that the effect of participatory and self-regulatory management on conflict management is mediated by cognitive and motivational mechanisms, and eagerly pointed. Since, according to Piedmont (2013), spiritual excellence is an attempt to have a mental and societal view of life and to construct a broad meaning and concept of the ultimate goal of life and death, so spiritual excellence can have both cognitive dimensions and mechanisms. Be motivational mechanisms. Also, spirituality is associated with an increase in certain tendencies and strengthens convergence. In fact, it overcomes individuality. Since conflicts are mainly arising from individualities and individualities end in divergence, participatory management and selfregulation through improving spirituality and spiritual excellence can lead to improved conflict management in the organization. Therefore, spiritual excellence is a good mediator between participatory management and self-regulation with conflict management. 
The most important limitations of the present study include the use of self-report tools, the limitation of the research community to teachers in districts 1 and 2 of Urmia, the lack of review of results by gender and little research background on the relationship between research variables. As a result, it is suggested that interviews be used in future research to collect data, if possible. The same research should be done on teachers in other cities or even on administrators and students and its results should be compared with the results of the present study. The last suggestion is to examine the relationships of variables by gender. Based on the results, it is suggested that planners and education officials design programs to improve conflict management based on the results of this study and similar studies. Another suggestion, considering the role and importance of conflict management in organizational performance and effectiveness, is to promote it through participatory and self-regulatory management workshops. The latest proposal is to hold in-service courses on conflict management, participatory management, self-regulation and spiritual excellence virtually and electronically for teachers and even other staff in the education organization. 


\section{References}

Abolghasemi A, Ariapooran S, Taherifard M. (2016). The role of spiritual transcendence in predicting the mood and life satisfaction students. Iranian Journal of Culture in the Islamic University. 5(4):515-536.

Andreoni A, Chang H. (2019). The political economy of industrial policy: Structural interdependencies, policy alignment and conflict management. Structural Change and Economic Dynamics. 48:136-150.

Arman M, Ahmadi E, Khosravilaghab Z. (2015). Investigation the role of win-win strategy of conflict management and mental intelligence in the perception of employees from organizational justice, studied sample: employees of Bushehr port and maritime organization. Journal of Strategic Management Research. 21(58):53-73.

Behmel S, Damour M, Ludwig R, Rodriguez M J. (2018). Participative approach to elicit water quality monitoring needs from stakeholder groups - An application of integrated watershed management. Journal of Environmental Management. 218:540-554.

Bouffard T, Boisvert J, Vezeau C, Larouche C. (1995). The impact of goal orientation on self - regulation and performance among college students. Educational Psychology. 65(3):317-329.

Caber M, Unal C, Cengizci AD, Guven A. (2019). Conflict management styles of professional tour guides: A cluster analysis. Tourism Management Perspectives. 30:89-97.

Ebrahimi A. (2014). Leadership styles and conflict management styles: An exploratory study. Journal of Social Issues \& Humanities. 2(1):151-156.

Entezami Bayan N, Ahghar G, Shabani H. (2017). The effect of self-regulated learning on conflict resolution styles in guidance school students. Journal of New Educational Approaches. 12(1):110-129.

Etebarian A, Poorvali Z. (2008). Determining the relationship between self-control and conflict resolution strategies among administrative staff of Khorasgan Azad University (Isfahan). Journal of New Approaches in Educational Administration. 1(2):111-130.

Fallahi V, Mikaeli N, Atadokht A, Ahmadi Sh. (2019). The role of self-regulation and alienation in predict educational achievement motivation of students. Shenakht Journal of Psychology and Psychiatry. 6(5):72-82.

Farzadnia F. (2012). The impact of emotional intelligence on conflict-handling styles among the head nurses of Milad hospital, Tehran. Journal of Ilam University of Medical Sciences. 20(2):53-61.

Feyzi M, Chopani H, Hayat AA. (2009). Investigating the relationship between managers 'management styles and creativity of high school teachers of Sanandaj city. Quarterly Journal of Educational Leadership \& Administration. 3(3):103-123.

Ghorbani R, Foolad Chang M. (2015). The relation of self-regulation and communal mastery to psychological wellbeing. Research in School and Virtual Learning. 2(8):31-42.

Hasanpour M, Izadian Z, Izadian M, Gholami Motlagh M. (2015). Relationship between nurses' conflict management styles and critical thinking skills in the clinical setting. Iranian Journal of Nursing Research. 10(4):58-66.

Hastings T J, Kavookjian J, Ekong G. (2018). Associations among student conflict management style and attitudes toward empathy. Currents in Pharmacy Teaching and Learning. 11(1):25-32.

Jafari S, Mollaei Z. (2019). Mediating role of self-regulated learning strategies for spiritual intelligence and academic achievement. Iranian Journal of Medical Education. 19:424-432

Jago AG. (2017). A contrarian view: Culture and participative management. European Management Journal. 35(5): 645-650.

Khoshtinat V. (2014). Survey of religious coping style in PNU students with an emphasis on spiritual elevation. Medical Ethics Journal. 8(30):133-153.

Kordi M, Aftab Azari M. (2010). Investigating the effect of workplace spirituality on participatory management process (suggestion system) (Case study: Tehran Municipality staff). 10th National Conference on Proposals, Tehran: University Jihad, Faculty of Management of University of Tehran.

Lace JW, Haeberlein KA, Handal PJ. (2017). Five-factor structure of the spiritual transcendence scale and its relationship with clinical psychological distress in emerging adults. Journal of Religions. 8:1-14.

Memmott-Elison M,Padilla-Walker LM, Yorgason JB, Coyne SM. (2020). Intra-individual associations between intentional self-regulation and prosocial behavior during adolescence: Evidence for bidirectionality. Journal of Adolescence. 80:29-40.

Muller NM, Seufert T. (2018). Effects of self-regulation prompts in hypermedia learning on learning performance and self-efficacy. Learning and Instruction. 58:1-11. 
Ormond PAD, Telhada J, Putnik G. (2019). Application of CE principles in design of an integrated participative management system to support for urban freight distribution planning: MISPPUFD model. Procedia CIRP. $84: 22-27$.

Piedmont RL. (1999), Dose spirituality represent the sixth factor of personality? Spiritual transcendence and the fivefactor model. Journal of Personality. 67(6): 985-1013.

Piedmont RL. (2013). The relevance of spiritual transcendence in a consumer economy: The dollars and sense of it. Journal of Social Research and Public. 4(2):59-77.

Qaysi SJA. (2018). A review of emotional intelligence and conflict management styles towards leadership in the workplace. International Journal of Computer Science and Information. 68:15-21.

RajabiFarjad H, Eghbalpur S. (2017). Assess the readiness of schools for the establishment of participatory management (Case Study: Secondary schools of Hamadan). Iranian Journal of Public Administration Mission. 7(3):33-43.

Rogers A A, Ha T, Byon J, Thomas C. (2020). Masculine gender-role adherence indicates conflict resolution patterns in heterosexual adolescent couples: A dyadic, observational study. Journal of Adolescence. 79:112-121.

Rolkova M, Farkasova V. (2015). The features of participative management style. Procedia Economics and Finance. 23:1383-1387.

Salimi Sh, Karaminia R, Esmaeili A A. (2011). The Study of personality traits, management styles \& conflict management in a Military Unit. J Mil Med. 13 (1):11-16.

Sandstrom P, Pahlen TG, Edenius L, Tommervik H, et al. (2003). Conflict resolution by participatory management: Remote sensing and GIS as tools for communicating land-use needs for reindeer herding in Northern Sweden. Journal of Human Environment. 32(8):557-567.

Silvius G. (2017). Sustainability as a new school of thought in project management. Journal of Cleaner Production, 166: 1479-1493.

Taghizadeh Z, Ebadi A, Dehghani M, et all. (2017). A time for psycho-spiritual transcendence: The experiences of Iranian women of pain during childbirth. Women and Birth. 30(6):491-496.

Thomas KW, Kilmann RH. (1974). Thomas-Kilmann Conflict mode instrument. Tuxedo: NY: Xicom.

Tourani S, Ahmadi B, Karami A. (2014). The correlation between nurses' conflict and head nurses' emotional intelligence in the emergency ward of teaching hospitals affiliated to Iran University of Medical Sciences. Journal of Health Promotion Management. 3(3):37-46.

Vashisht R, Singh K, Sharma S. (2018). Emotional intelligence and its relationship with conflict management and occupational stress: A meta-analysis. Pacific Business Review International. 11(4):30-38.

Vega D, Torrubia R, Marco-Pallares J, et all. (2020). Metacognition of daily self-regulation processes and personality traits in borderline personality disorder. Journal of Affective Disorders. 267:243-250.

Viseh S M, Kimiagar A M. (2017). The effect of spirituality environmental factors on organizational conflict (Case study: Cultural units of the ministry of culture and Islamic guidance of Ilam province). Journal of Ilam Culture. 18(54-55):73-88. 